HANNAH RYLEY

Oxford University

\title{
Constructive parchment destruction in medieval manuscripts
}

\begin{abstract}
This article argues that in the fifteenth century, many manuscripts were physically recycled, and that this recycling is symptomatic of interest in sustaining books. In the case studies explored here, unwanted or old texts became valued for the physical qualities of the parchment on which they were written. Case studies of recycled manuscripts, including flyleaves, pastedowns, limp covers and palimpsests, are presented to argue that many books were made (and re-made) in sustainable ways. Although recycled books, and bits of books, have been mentioned fleetingly by many scholars, and studied as treasures or for the scraps of text they preserve, this article focuses particularly on the practices and processes of medieval book recycling. Research into recycled books thus adds to the history of material culture, to the history of the book, and to debates about the sustainability and durability of media today: we can learn from the practices and processes of the past.
\end{abstract}

\section{KEYWORDS}

sustainability recycling medieval manuscripts materiality fragments

In the fifteenth century, English book producers recycled old parchment in new manuscript books, in order to promote the durability of the new books. When parchment was reused constructively to enhance the sustainable potential of manuscripts, at the same time it was put at risk of destruction. I argue that these reuses of parchment are productive, what I call here 'constructive destruction'. At the point that book producers recycled parchment in books, it was no longer valued as a carrier of text, and instead came to be valued as a piece of material. While some recent scholarship has focused on the 'misuse' of books and 'creative' book destruction (Partington and Smyth 2014), reuses of parchment in medieval manuscript books often took the form of protective measures, such as flyleaves, pastedowns, limp covers and 
quire guards. Although such forms of parchment protection are well-attested in the post-Reformation, post-Dissolution period, and there have been notable studies of early modern parchment reuse (Ker et al. 2000; Pearson 2000), this is not just an early modern phenomenon; there were medieval precedents for the reuse of parchment books. This article draws attention to the pre-Reformation period, and focuses on parchment from former books that was recycled in the fifteenth century to sustain other manuscripts the constructive destruction or reuse of parchment for improving another manuscript's chances of survival.

The recycling of parchment in fifteenth-century English book production is demonstrated here through close readings of surviving manuscripts, which were selected from surveys of substantial collections in Oxford and Worcester. The case studies were selected as good examples of parchment recycling in the form of flyleaves, pastedowns, limp covers and palimpsests used as quire guards. In each case, the parchment was reused to enhance the new manuscript's sustainable potential. These components are part of the 'stratigraphy', or layered nature, of medieval manuscripts (Gumbert 2004: 18). In manuscripts with visibly recycled parchment components, such as reused flyleaves that still bear writing from a former book, the added reused parchment may be easily differentiated from other stages of production and readily visible as a discrete layer of evidence. However, where recycling has resulted in the erasure, rupture, or fragmentation of evidence, such as palimpsests, or any other heavily worn components, the stratigraphy may be far more complex.

The manuscripts discussed here date to fifteenth-century England, a period when book production was gathering pace (Gillespie and Wakelin 2011: 1-11; Pearsall 1989: 1-10). The cluster of trades surrounding the making of books was diversifying and, at the same time, becoming increasingly organized, even specialized (Bell 1937: 313). This was the century that saw the rise of paper and print technology in England. At the professional end of the market, books were mostly made in urban centres of production. Books were usually bespoke, artisanal products, made for a particular patron to their specifications, though towards the end of the century some were produced on a speculative basis. By then, different classes of people, such as merchants, could increasingly afford books. In universities, students and scholars continued to write extensively, and even to make their own rudimentary bindings for notebooks or personal copies of books. There were also other amateurs engaging with 'do-it-yourself modes of production' and making books for themselves (Boffey 2012: 20). The following case studies investigate a selection of manuscripts from this varied fifteenth-century culture of book production and use. These examples demonstrate that, at this time, there was a widespread culture of book recycling, and that a key feature of this culture was the constructive destruction of parchment in service of sustainable book production. 
In this increasingly mixed market, manuscripts could be made to a range of specifications. There were, of course, beautifully decorated, gilded books made to expensive and exacting standards, such as ornate Books of Hours, Bibles and other precious manuscripts. However, at the other end of the spectrum, there were also cheaper choices available, which resulted in the possibility of producing lower-grade manuscripts (Kwakkel 2011: 183, 191). These cheaper book-production strategies more often involved recycling. Books made to a lower grade often included (but were not limited to) texts for learning, teaching, and preaching, as well as legal, scientific, culinary, medical and business texts. The case studies here represent a range of texts, including works on logic, law, astrology, astronomy, medicine, the administration of Royal Forests, and the religious poem 'The Prick of Conscience'. Although sustainable methods had long been a part of production, this article focusses on fifteenth-century books in which parchment was constructively destroyed in various recycled forms.

Pieces of parchment were reused in the fifteenth century in myriad, ingenious ways. Outdated, unfashionable or simply dilapidated manuscripts were taken apart and recycled for their component parts. Parchment leaves, taken from broken books, were amenable to reuse as flyleaves, pastedowns and spine padding in other books. There have been some prior studies of this range of material, such as a study of artefacts in Swedish archives, however, it is limited to these binding-based reuses (Brunius 2013: 24). Another area of fragment studies that has attracted some attention is the cutting-out of miniatures (de Hamel 1996). In addition to these phenomena, smaller pieces of recycled parchment in books are used as reinforcing strips, or scraps added as inserts or extensions, and larger pieces are used as quire-guards, wrappers or palimpsests.

Outside of books, parchment has been recycled in a surprising array of other reuses. It was often completely obliterated by such reuses, for example in domestic uses for cooking or cleaning. There are some rare surviving examples of parchment reuse: for example, in Norway there is a bishop's mitre constructed from four pieces of parchment, dated to c. 1270 (Copenhagen, Den Arnamagnænske Samling, AM 666 b 4to; Kwakkel 2013). This was designed to create a stiff parchment structure that would then be covered with cloth. Written on the parchment is a Norwegian translation of a French lai about two lovers. Another example of manuscript recycling is fragments sewn by nuns into the hems of dresses in Lüneberg. This cache of ornate dresses was made to clothe religious statues, and their hems are lined with scraps from over 30 different manuscripts, including liturgy, hymns and law texts (Lähnemann 2014). It has also been reported that leaves of a liturgical music manuscript were used to line hatboxes and organ cases (Craig-McFeely 2007-08: §2). These surviving examples of esoteric parchment recycling are unusual and reuses outside books typically resulted in the total destruction of parchment. 
Both outside books and in them, it is the common qualities of parchment that enabled its reuse. Like the reuses of parchment to strengthen a bishop's mitre, or line dresses, reuses in books take advantage of the same material properties. The key qualities of parchment that made it so useful in these contexts are its 'lightness and flexibility [...] high tearing strength [...] [and] exceptional long-term stability' (Reed 1972: 5). It can also be stitched or glued easily. These material characteristics made it possible to recycle parchment in many ways. Of course, both outside books and in them, parchment was susceptible to destruction: it turns to jelly when wet, can decompose, or it can be burnt, cut up, or worn away. For reuses in books, in the right conditions, parchment could last for a very long time. As Nicholas Pickwoad has noted, parchment 'is durable and resistant to wear in almost all areas of book work' (2000: 1). When fifteenth-century people did choose to recycle parchment in new books, they often used it in ways that promoted the new book's 'long-term stability' in a process of constructive destruction.

One of the commonest ways that the makers and users of books promoted their physical stability over time was by protecting the main book block with flyleaves and pastedowns. They were often made of recycled parchment, and survive relatively commonly in medieval manuscripts (for Oxford-specific survival rates, see Pearson 2000: vii). Flyleaves take the form of leaves that can be turned freely, whereas pastedowns are at least partly fixed with adhesive to the book's boards or covers. Both are used in manuscripts to bracket the book block and have a protective role. Specifically, the flyleaves or pastedowns can protect the main book block from being abraded by the knots which are a vital part of more substantial wooden bindings and sit slightly proud of channels on the inside face of the board. Defending the main text from being rubbed into holes is one of the key functions of both flyleaves and pastedowns. Their other function is general protection from rubbing by the heavy outer boards. It has been noted that flyleaves and pastedowns also specifically help to protect any expensive decoration, displayed prominently on the first folio, from rubbing caused by contact with binding boards (Smith 2000: 21). Therefore, both flyleaves and pastedowns were added to manuscripts in an effort to maintain the material integrity of the book, and their own texts and physical presence were gradually worn away.

Binders (and other book-makers) secured material from superfluous deeds, letters, superseded canon law, old liturgy or other simply worn-out books for guarding the beginnings and endings of their manuscripts with flyleaves or pastedowns (Ivy 1958: 5253). Such material might be ornately decorated, and written with high-grade handwriting, such as textura script, or it might be made to a low grade of production, scruffy, or even take the form of disintegrating leaves from old books. Those bookmakers might also use abandoned drafts or leaves on which ruling, writing, or drawing were half finished, or in which there were errors. Sometimes these pieces of material required extra effort to trim or fold in order to fit the new context in a different book. 
These pieces of parchment (or paper) were remnants of other projects, or were taken from broken books, and were redeployed as flyleaves or pastedowns in order to protect the main text or texts, and therefore to sustain the rest of the new manuscript.

The reuse of parchment as flyleaves and pastedowns took advantage of its physical properties, in particular, its resilience to wear and tear. An example of a very old flyleaf bound in to a manuscript in the fifteenth century, is found in a book containing fourteenth-century texts and tables of logic (Worcester Cathedral Library, MS F. 72). A tenth-century leaf, taken from a Gospel book, has been unevenly folded and sewn into the front of this manuscript (ff. 1-2; Thomson and Gullick 2001: 46). The binding dates to the fifteenth century, and is not thought to be original. At this point, the leaf was bound in with the main book block. The flyleaf is a highly decorative folio in its own right, with arches, grotesque faces and colourful inks. The treatment of this leaf seems casual: though it may already have been well-worn by the fifteenth century, it is noticeably darker, dirtier parchment, and has been folded at an odd angle and sewn in crookedly. There is no special reverence for the Gospel text on the old piece of parchment, and no correlation between that older text and the tables of logic in the main book block. Nonetheless, the leaf from a Gospel book has continued to coexist and to act in concert with the sleeves of the over-cover and the pastedowns to protect the rest of the manuscript from damage.

Another durable, protective leaf, this time a pastedown, is adhered inside the front boards of a manuscript of legal texts and Royal Forest administration (Oxford, Bodleian Library, MS Lyell 32). While the main texts were written in cursive hands in the second half of the fifteenth century, the pastedown was composed earlier in the same century in large module textura, in black, red and blue inks, and is replete with musical notation on four line staves. It was part of a noted Gradual, and contains parts of the 'Agnus Dei' and 'Credo' (de la Mare 1971: 80). From its layout, it is evident that the pastedown was once much larger and has been trimmed down, probably to fit this book (approximately $200 \mathrm{~mm} \times 130 \mathrm{~mm}$ ). The binding is careworn and the sewing supports have broken off where they should bridge the gap between the boards and the main book block. Lumpy knots underlie the pastedown where the sewing supports have been fed through channels in the board. This particular example demonstrates the way in which the parchment pasted over the lumpy knots has been rubbed between the wooden board and the main body of the book. This pastedown, made from another book, has been used here as a defensive measure: it protects the main body of the new book by being gradually destroyed.

Parchment can offer protection in other ways, for instance when wrapped around books as limp covers (also known as limp bindings or wrappers). In the most general sense, these bindings are coverings that do not have wooden boards, as suggested by one of 
the most common medieval terms for these structures - libri sine asseribus (literally, 'books without boards') (Ligatus n.d.). Limp binding is just one type of binding among many medieval binding formats, and in the medieval period, limp covers were constructed from soft leather, fabric or parchment. Moreover, like flyleaves or pastedowns, wrappers were sometimes made from parchment that had been previously used. Like other protective formats, limp covers also testify to parchment's capacity to be reused, sometimes to destruction.

So why make a binding without boards? Limp covers have been emphasized as a 'remarkably simple construction', which '[required] little or no adhesive and hence were produced easily in large numbers' (Reed 1972: 167). Yet, though many limp covers were simple, many surviving examples have also been recognized as 'practical bindings of sound and even sophisticated construction' (Gullick and Hadgraft 2008: 108). What has been identified as the sophistication of limp covers lies in their very simplicity. In addition, Christopher Clarkson also points out other streamlined, pragmatic aspects of limp binding design, which include their 'light weight, mechanical yielding qualities, lack of distortion in varying atmospheres and the durability of their component materials' ([1982] 2005: 1). Limp covers draw on the particular material qualities of parchment. When compared with other more substantial and expensive kinds of bindings and coverings, which during the fifteenth century included leather covers over wooden boards, treasure bindings, textile bindings, girdle-books, chemise or over-covers, limp covers were cheaper and easier to make: they were an elegantly simple option for covering and protecting books.

In one example of a limp cover, the wrapper is now worn to a grubby brown colour and is waxy with wear and stains on the outside from its long service protecting the contents. The book is a fifteenth-century scientific miscellany, including astrological texts in Latin and English, which now takes the form of a collection of loose quires wrapped in a limp parchment binding (Oxford, Bodleian Library, MS Lyell 36; de la Mare 1971: 92-101). The thirteen quires of parchment and paper are worn, particularly at the edges, and the quality of the parchment used for the cover is low - it is thick, with follicle marks and a hole - but it is practical for this purpose. The wrapper has turn-ins on all four sides (lower edge: $115 \mathrm{~mm}$; upper edge $50 \mathrm{~mm}$; overlapping these, left and right edge turn-ins $80-90 \mathrm{~mm}$ ). The quires were originally stab-stitched and secured into the parchment cover by two or three thin strips of parchment per quire, doubled-up for strength. Evidence of this can be seen in the multiple stab-holes that remain, punctured through the parchment, running along the spine of the binding. Although it is unclear whether the attaching strips or the limp binding are made of recycled material (they do not bear text or images or other evidence of former use), it is clear that this parchment has been salvaged for reuse. 
Wrappers were often constructed from recycled material, tangible examples of reuse. The cover of a roughly made manuscript of astrological tracts and tables has been fashioned from a leaf of a fourteenth- or fifteenth-century religious treatise in French (Oxford, Bodleian Library, MS Ashmole 366; Black and Macray 1845-66: 281-82). This is a typical example of the overt recycling of written-on (or even, sometimes, decorated) parchment as covering material. In the case of this manuscript, the whole book exhibits low production values, with stiff parchment leaves and roughly executed writing and diagrams. However, in spite of this low-grade context, some care has been taken to secure the cover, with thick strips used in three places along the spine to fasten the wrapper to an additional parchment support. The cover also has small turn-ins at the top and bottom, and the back cover has a substantial flap. In common with many other limp-bound manuscripts made of recycled parchment, there has been no attempt to hide or scrape away the writing on the cover. It seems that the undertext visible on the cover was not a concern, and did not mislead people identifying the book's contents. The decision not to expend effort on scraping or neatening up the wrapper suggests that the key aim was expedient, no-frills reuse of material for a protective purpose.

These extant examples of limp covers are durable artefacts in their own right, possessed of a capacity for longevity. They draw on the material properties of parchment, and these surviving examples suggest their resilience. They were relatively cheap to produce, and could be made with simple stitching and efficient wrapping and folding methods. These techniques took very little training or time to achieve. Though simple, these techniques made holes and creases in the parchment taken from one book in service of another. During the fifteenth century, limp covers 'were increasingly used in place of wooden boards, especially on the sort of "cheap" books that were made out of paper and written in cursive hands' (Gillespie 2011: 162). The material used to produce limp covers was sometimes directly recycled from other books, used directly, constructively to sustain other manuscripts.

Salvaging material to make a wrapper or flyleaf is relatively straightforward, but making reclaimed resources reusable can involve substantially more effort. This effort is in evidence in the case of palimpsests, which are pieces of parchment that bore writing that was effaced to make way for a further campaign of writing. Palimpsests are commonly assumed to be rare by the fifteenth century; however, there are surviving examples of this technique from that period. The various scored marks and the faint ink residues left by the pen, inscribed into the surface of the parchment, are a strange reminder of what has gone before and the effort it must have taken to remove its presence. If the parchment was resilient enough to withstand it, palimpsests could be composed of multiple campaigns of scraping (or washing) and writing (Beal 2008: 279). Palimpsests represent a distinct choice to recycle by the reusers (or at least the makers) of the material. In contrast with the relatively easy efforts required for using parchment 
as flyleaves, pastedowns or limp covers, palimpsests represent a more concerted - and sometimes more destructive - resourcefulness.

How did medieval palimpsest-makers convert a written piece of parchment into a reusable writing support? Erasing writing was not as easy in the fifteenth century as it is today. Without any ink corrector pens, Tipp-Ex fluid or delete buttons to hand, scribes usually relied on their 'penknife' for removing mistakes (Whalley 1975; Gullick 2006). With this knife, they would scratch and scrape away the topmost, ink-marked layer of parchment. This could be a fiddly job, especially with fine, thin, well-made parchment. This skill was the basis of the more intensive job of palimpsesting by scraping. Whatever the quality of the parchment, scraping it risked strewing scars across the surface, creating thin or rough patches, and even - when the knife slipped - holes that went right through. Parchment scraped until it was so fragile that it disintegrated can be seen in a fifteenth-century copy of 'The Prick of Conscience' (Oxford, Bodleian Library, MS Rawl. C. 35, f. 28). ${ }^{1}$ A more unusual example of what appear to be 'knife-trials', where perhaps the knife was tested, can be seen in a series of inch-long slits cut into the parchment in the Hereford Missal (Worcester Cathedral Library, MS F. 161, ff. 230, 234; Thomson and Gullick 2001: 110). Evidently then, with sharp knives to hand, scraping down parchment for reuse was a task that involved care and attention, since it risked destroying the parchment and rendering it useless.

Text-bearing parchment could also be ground down by repeating the final stage of production: polishing with pumice. Both the scraping and smoothing processes are depicted in a fourteenth-century Italian image, which suggests that these processes may have been undertaken side by side in a workshop (Bologna, Biblioteca Universitaria, MS 1456, f. 4r; see O'Daly 2013). In addition to these techniques, which are most commonly associated with palimpsest-making, the removal of ink could be achieved by washing. This method has been considered to be more likely for a second (or third) effacement of ink than scraping (Declercq 2007: 7-8). Rather than mechanically removing the upper surface, washing involved the application of powerful chemical concoctions, including ingredients such as unslaked lime, vitriol or alum. Each of these techniques took an enormous amount of effort, additional resources, and preparation, in order to efface the undertext.

In an unusual fifteenth-century example, parchment was palimpsested and then used as quire guards (Oxford, Hertford College, MS e. 4). In this paper manuscript of scientific texts, there are fourteen palimpsest quire guards. The undertexts on these leaves have been identified as known extracts from Wycliffite Sunday epistle sermons (OgilvieThomson 1991: 37). These were written on parchment, which was then rubbed and used

\footnotetext{
${ }^{1}$ I am grateful to Dr Daniel Sawyer for bringing this manuscript to my attention.
} 
to support, protect and strengthen the paper quires. The parchment encloses each quire (or booklet) of paper, all of which are bound together to form the book block. The book has been dated to $c .1400$, and the scientific texts include works on astronomy and medicine. These were written in a number of scripts, ranging from neatly executed small anglicana-influenced secretary handwriting, to larger sprawling secretary hands. The palimpsested leaves have been rotated clockwise by 90 degrees, and bound in to the manuscript either to enclose the outside or sit in the middle of a quire (at ff. 2 [which is illegible], 19, 42, 43, 50-51, 58, 59, 108, 125, 138-39, 195, 196 and 209). Five are complete leaves, which have been trimmed (complete leaves around the outside of quires: ff. 43 and 58, 50 and 51, 108 and 125, 196 and 209; complete leaves in the middle of a quire: ff. 138-39), and five are individual half leaves (ff. 2, 19, 42, 59 and 195).

Attention to protecting the new text and its functionality for years to come can be inferred from the presence of the quire guards. However, the curious thing about this manuscript is that palimpsested parchment was used for this protective purpose. There has been a considerable input of effort into scraping down the parchment for reuse. Perhaps this effort was felt to be worthwhile: an interest in scraping the parchment might have been reinforced by the desire to erase the Wycliffite undertexts, which were regarded as questionable, heretical works. To provide fully enclosing quire guards throughout a manuscript (of 254 leaves in total) demands a lot of material, so recycling old parchment makes some sense. However, unless the book-producers bought the material or somehow came by 'ready-made' palimpsests, they must have scraped them down themselves. If so, the time and effort needed for scraping the sermon-bearing leaves were clearly available to the makers of this manuscript in a way that fresh, new parchment was not. This manuscript, in spite of the somewhat variable hands in the main texts, was designed to look relatively smart and to last. The manuscript makers' attention to detail resulted in quires that were protected with carefully neatened recycled parchment guards. So, the recycling of parchment as palimpsests was partly guided by aesthetic considerations, as well as expedience and cost-saving.

As this case study suggests, palimpsests can be seen as one of many 'cheaper' choices that became increasingly available in the production of books, in part through recycling. Yet scraping away text runs the risk of damaging the material beyond all functionality. Sometimes people made more of an effort to destroy the undertext completely (as in the example of neatly scraped quire guards in Oxford, Hertford College, MS e. 4), but sometimes they made less. Sparingly scraped palimpsests (such as some of those in Oxford, Bodleian Library, MS Rawl. C. 35, which still carry glimpses of undertexts) confirm the idea that the effort this process entailed was more significant than other, less labour-intensive kinds of recycling. This effort, indicated by the full or partial erasure of undertexts, suggests that reusers sometimes deliberately obliterated undertexts, but also that sometimes they were guided by other considerations such as aesthetics or 
expedience. While palimpsesting destroys earlier writing and ruling schemes (though some slight traces may remain), through this process the parchment itself is constructively reused to protect other parts of books.

These case studies of fifteenth-century manuscripts have demonstrated the material properties of parchment that made it so desirable for recycling, and so useful for protecting and sustaining books. The repurposing of parchment from old books was not only a post-Reformation phenomenon; parchment was also reused in books in the fifteenth century. Not only did fifteenth-century book producers choose to recycle parchment; they reused it in ways that promoted the new manuscript's durability. Reuses for protection could take the form of flyleaves, pastedowns, limp covers or quire guards, and the parchment recycled to make these components was sometimes drawn from other books. The recycling of parchment is perhaps most readily apparent in examples where the earlier text or undertext is still visible, for instance the flyleaf made from a noted Gradual, or the French religious treatise on a limp cover. All of the reuses of parchment discussed here draw on the 'long-term stability', the resilience, durability and the material properties peculiar to parchment as a material, while simultaneously destroying a particular earlier book as a structure.

But, as we have seen, in the process of recycling parchment and reusing it as a component in a book, it is dislocated, transformed and even destroyed itself. The dislocation from a previous context was often compounded by physical transformation: cutting, folding, sewing, adhering, scraping, washing. In many of the case studies, parchment reused for protective purposes has been gradually rubbed, scuffed and worn over time, and this has led to visible damage. Whether it was a quick act of transformation brought about by human hands, or long-term, gradual wear and tear, these changes were destructive to parchment. Paradoxically, they were also constructive forms of destruction. The case studies indicate the attention and effort taken by bookmakers to enhance and promote a manuscript's chance of survival, whether that involved adding flyleaves or pastedowns to bear the brunt of abrasion, or wrapping a book in a protective limp cover, or carefully scraping down parchment for reuse as a neat, palimpsest quire guard. In fifteenth-century book culture, these destructive reuses of parchment from one book in turn helped to sustain other manuscripts.

\section{MANUSCRIPT REFERENCES}

Copenhagen, Den Arnamagnænske Samling, AM 666 b 4to, http://handrit.is/ en/manuscript/view/AM04-0666-b. Accessed 23 January 2017.

Oxford, Bodleian Library, MS Ashmole 366. 
MS Lyell 32.

MS Lyell 36.

'The Prick of Conscience', MS Rawl. C. 35.

Oxford, Hertford College, MS e. 4.

Worcester, Worcester Cathedral Library, MS F. 72.

MS F. 161.

\section{REFERENCES}

Beal, Peter (2008), A Dictionary of English Manuscript Terminology 1450-2000, Oxford: Oxford University Press.

Bell, Henry Esmond (1937), 'The price of books in medieval England', The Library, 4th series, 17, pp. 312-32.

Black, William H. and Macray, William D. (1845-66), A Descriptive, Analytical, and Critical Catalogue of the Manuscripts Bequeathed unto the University of Oxford by Elias Ashmole, Oxford: Oxford University Press.

Boffey, Julia (2012), Manuscript and Print in London c. 1475-1530, London: The British Library.

Brunius, Jan (2013), From Manuscripts to Wrappers: Medieval Book Fragments in Swedish National Archives, Skrifter utgivna av Riksarkivet 35, Växjö: Davidsons Tryckeri.

Clarkson, Christopher (1982 [2005]), Limp Vellum Binding and Its Potential as a Conservation Type Structure for the Rebinding of Early Printed Books: A Break with Nineteenth and Twentieth Century Rebinding Attitudes and Practices,

Oxford: Christopher Clarkson. Craig-McFeely, Julia (2007-08), 'Digital image archive of medieval music: The

evolution of a digital resource', Digital Medievalist, 3, http://digitalmedievalist.org/journal/3/mcfeely/. Accessed 23 January 2017. Declercq, Georges (2007), 'Introduction: Codices Rescripti in the early medieval west', Early Medieval Palimpsests, Bibliologia, vol. 26, Turnhout:

Brepols Publishers, pp. 7-22. Hamel, Christopher de (1996), Cutting Up Manuscripts for Profit and Pleasure, 
Charlottesville: Book Arts Press. Gillespie, Alexandra (2011), 'Bookbinding', in Alexandra Gillespie and Daniel

Wakelin (eds), The Production of Books in England 1350-1550, Cambridge:

Cambridge University Press, pp. 150-72. Gillespie, Alexandra and Wakelin, Daniel (2011), 'Introduction', in Alexandra

Gillespie and Daniel Wakelin (eds), The Production of Books in England

1350-1550, Cambridge: Cambridge University Press, pp. 1-11. Gullick, Michael (2006), Pen in Hand: Medieval Scribal Portraits, Colophons and

Tools, Walkern: Red Gull Press. Gullick, Michael and Hadgraft, Nicholas (2008), 'Bookbindings', in Nigel

J. Morgan and Rodney M. Thomson (eds), Cambridge History of the Book in Britain, II: 1100-1400, Cambridge: Cambridge University Press, pp. 95-109.

Gumbert, Johan Peter (2004), 'Codicological units: Towards a terminology for the stratigraphy of the non-homogeneous codex', Segno e Testo: International Journal of Manuscripts and Text Transmission, 2, pp. 17-42.

Ivy, G. S. (1958), 'The bibliography of the manuscript book', in Francis Wormald and C. E. Wright (eds), The English Library Before 1700, London: The Athlone Press, pp. 32-65.

Ker, Neil R., Rundle, David and Mandelbrote, Scott (2000), Fragments of Medieval Manuscripts Used as Pastedowns in Oxford Bindings: With a Survey of Oxford Binding $c$. 1515-1620, 3rd series IV, Oxford: Oxford Bibliographical Society.

Kwakkel, Erik (2011), 'Commercial organization and economic innovation', in Alexandra Gillespie and Daniel Wakelin (eds), The Production of Books in England 1350-1550, Cambridge: Cambridge University Press, pp. 173-91.

— (2013), 'A love story hidden in a hat', http://erikkwakkel.tumblr.com/ post/55554381477/a-love-story-hidden-in-a-hat-you-are-looking-at-a. Accessed 23 January 2017.

Lähnemann, Henrike (2014), 'Texts and textiles: Manuscript fragments in medieval dresses', Workshop for Manuscript and Text Culture, Queen's College, Oxford, 4 June.

Ligatus (n.d.) 'The language of bindings thesaurus', http://www.ligatus.org. uk/lob/. Accessed 23 January 2017. 
Mare, Albinia Catherine de la (1971), Catalogue of the Collection of Medieval Manuscripts Bequeathed to the Bodleian Library, Oxford by James P. R. Lyell, Oxford: Clarendon Press.

O'Daly, Irene (2013), 'Secrets of the page: Palimpsests', http://medievalfragments.wordpress.com/2013/02/15/secrets-of-the-page-palimpsests/. Accessed 23 January 2017.

Ogilvie-Thomson, Sarah Jane (1991), The Index of Middle English Prose, Handlist VIII: Manuscripts containing Middle English Prose in Oxford College Libraries, Cambridge: Brewer.

Partington, Gill and Smyth, Adam (2014), Book Destruction from the Medieval to the Contemporary, Basingstoke: Palgrave Macmillan.

Pearsall, Derek (1989), 'Introduction', in Jeremy Griffiths and Derek Pearsall (eds), Book Production and Publishing in Britain 1375-1475, Cambridge: Cambridge University Press, pp. 1-10.

Pearson, David (2000), Oxford Bookbinding 1500-1640: Including a Supplement to Neil R. Ker's Fragments of Manuscripts Used as Pastedowns in Oxford Bindings, Oxford: Oxford Bibliographical Society.

Pickwoad, Nicholas (2000), 'The use of fragments of medieval manuscripts in the construction and covering of bindings on printed books', in Linda L. Brownrigg and Margaret M. Smith (eds), Interpreting and Collecting Fragments of Medieval Books, Los Altos Hills, CA: Anderson-Lovelace, pp. 1-20.

Reed, Ronald (1972), Ancient Skins, Parchments and Leathers, London: Seminar Press.

Smith, Margaret M. (2000), The Title Page, its Early Development, 1460-1510, London: The British Library.

Thomson, Rodney M. and Gullick, Michael (2001), A Descriptive Catalogue of the Medieval Manuscripts in Worcester Cathedral Library, Cambridge: Brewer.

Whalley, Joyce I. (1975), Writing Implements and Accessories from the Roman Stylus to the Typewriter, London: David \& Charles.

\section{CONTRIBUTOR DETAILS}

Hannah Ryley is the Wilkinson Assistant Dean \& Junior Research Fellow at Worcester 
College, Oxford. Her thesis was supervised by Daniel Wakelin. She has taught the undergraduate medieval literature course at Oxford and has co-taught seminars on the material text 1550-1800. Her research focuses primarily on the materiality of fifteenthcentury manuscripts, with particular attention to the ways in which people reused and recycled their books. She is also interested in early print culture, object studies, ecocriticism and in storytelling outreach.

Contact: Worcester College, Walton St., Oxford, OX1 2HB, UK. E-mail:

hannah.ryley@worc.ox.ac.uk 